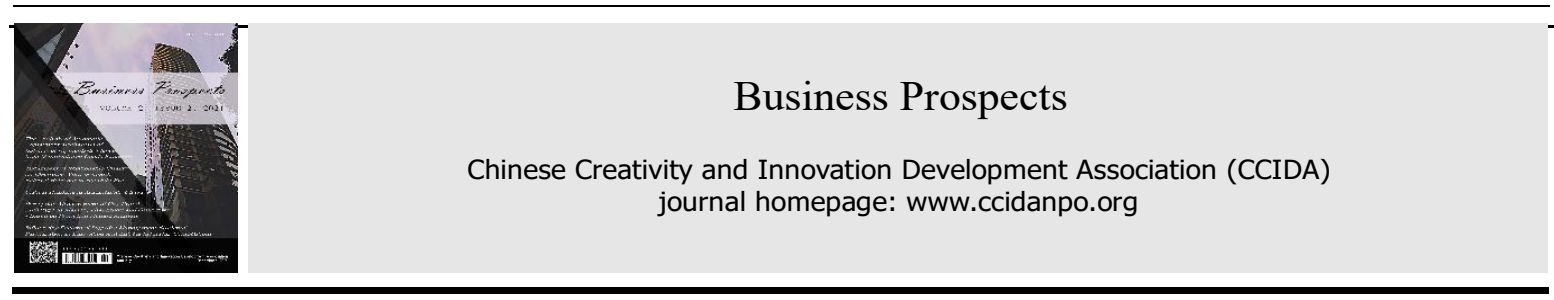

https://doi.org/10.52288/bp.27089851.2021.12.10

\title{
Critical Thinking in Argumentative Essays
}

\author{
Yina $\mathrm{Wu}^{1, *}$ \\ ${ }^{1}$ Xiamen University Tan Kah Kee College, Zhangzhou, Fujian, China \\ * Correspondence: sandywyn@xujc.com
}

Received: 2021.07.15; Accepted: 2021.10.30; Published: 2021.12.01

\begin{abstract}
The absence of critical thinking competency among college students has been one of the most widely studied subjects in China. This paper discusses the importance of critical thinking and suggests a three-step approach to cultivating critical thinking in developing argumentative essays, which includes before writingchoosing online resources as learning materials, during writing-choosing open, inspiring and controversial tasks, and post writing-teacher assessment.
\end{abstract}

Keywords: Critical Thinking Competency; Argumentative Essays; Teacher Assessment

\section{Introduction}

One of the most widely discussed concepts in college English educational reform in China is critical thinking. The fact that Chinese college students lack critical thinking competency is widely criticized by Chinese scholars and it's referred to as "critical thinking absence disease". Critical thinking has been defined differently from various perspectives. Tsui (2002) refers to critical thinking as a series of cognitive skills that students apply to 'identify issues and assumptions, recognize important relationships, make correct inferences, evaluate evidence or authority, and deduce conclusions. To connect critical thinking and writing, Barnawi (2011) defines critical thinking in second language (L2) writing as 'an ability to analyze facts, produce and organize ideas, maintain opinions, make comparisons, judge arguments, and solve problems using existing information, previous knowledge, experience, and world knowledge when writing'. He believes that students might be able to transform their ideas or arguments into their own texts if ideas or arguments operate based on existing information. If ideas or arguments come from students' previous knowledge or experience, students can articulate such ideas into their written work. The use of previous knowledge or experience is perceived as a facilitating tool for generating ideas or arguments when writing.

Critical thinking is defined by Paul and Elder (2006) as the process of analyzing and assessing thinking in order to improve it. The key to the creative side of critical thinking lies in restructuring thinking as a result of thoroughly analyzing and assessing it. Critical thinking is a set of intellectual skills and abilities which results in content mastery and deep learning and encourages students to search and process information with discipline. Students with critical thinking competency can think their way to conclusion, defend positions on complex issues, contemplate viewpoints from a variety of perspectives, analyze concepts, theories, and explanations, clarifying issues and conclusions, solve problems, transfer ideas into words, assess alleged facts effectively, and come to terms with the contradictions and inconsistencies in their own ideas and experience.

Within the range of definitions of critical thinking, two major domains are identified, cognitive (skills) and affective (disposition) factors. Critical thinking in the cognitive domain is described in terms of a set of higher order thinking skills such as evaluation, inference, analysis, while the disposition description involves the motivation to use critical thinking skills and includes elements such as truth-seeking, self-confidence and open-mindedness. In this paper, critical thinking is defined as an ability to analyze facts, organize and produce ideas, compare information and views, hold opinions, make judgment, and make convincing arguments when writing. 
In this information age, we are faced daily with tons of information, much of which is cunningly packaged to serve vested interest groups instead of the public good. It is, therefore, of great significance that students take charge of their own minds, recognize their own values, and take action to defend for their own and the good of others. Nold (2017) points out that it has been an indispensable component of the language teaching curriculum to develop students' critical thinking skills, as they help to foster students' abilities to analyze and evaluate information, as well as to make their own decisions related to their academic success. In English writing, writers must compose texts at the dual levels of language and content, which means English-as-a-foreign-language (EFL) writers must acquire corresponding critical thinking skills, and through them, deconstruct valued English texts and construct their own content on the two levels.

\section{Foster Critical Thinking in Developing Argumentative Essays}

Writing in a foreign language has always been regarded as a demanding task as it calls for the availability of EFL linguistic knowledge and automatic deployment of this knowledge. Producing a successful foreign language written text is no doubt a complex task since it requires simultaneous control over several language systems. Despite the significance of critical thinking competency in the process of writing construction, it is largely ignored in the conventional writing classroom, which primarily focuses on the teaching of linguistic competency like vocabulary or grammar or structure. In EFL writing contexts, teaching critical thinking skills is challenged by conventional classroom practices where teachers focus only on the contents of the textbooks, resulting in a scenario where teachers provide insufficient space for students' development of critical thinking. One possible reason might be that EFL teachers assume that because their students have not been taught to think critically and independently in their L1 writing, they may lack critical thinking and individualized voice in their L2 writing. Another reason may be that college EFL teachers have not paid much attention to the notion of critical thinking in their writing instructions as they often assume that their students are incapable of critically positing their voices, judgement, and beliefs into written texts. However, these assumptions are questionable and worthy of further investigation.

Liu and Stapleton (2014) found that Chinese college students taught counterargument gained critical thinking skills in analyzing and evaluating different opinions in academic writing. McKinley (2013) also suggested that argument-based writing was an optimal way to train students' critical thinking as it helped them analyze and evaluate different types of evidence and project authorial stances. The process of writing and critical thinking complements each other. Writing encourages students to think and analyze, thus improving their critical thinking. Critical thinking competency in writing refers to the abilities to accurately identify problems, comprehensively and objectively analyze and evaluate problems, explain reasons and propose solutions, and the ability to make a deep reflection on the writing process and prepare for the next writing task. Argumentative essays writing is an intensive activity that requires high-level thinking, from coming up of a title to working out the framework, to writing the essay and to revising it. The whole process calls for critical thinking. In fact, argumentative essays writing is an external manifestation of thinking.

Wingate (2012) offers a three-component model of argumentation, the first of which is analysis and evaluation of content knowledge, including the ability to find relevant information from background knowledge to support the writer's argument. In other words, the writer must provide enough support, by either criticizing or evaluating. The second component is the writer's development of a position, where the writer needs to imply or state the adopted position, voice, or stance. The extent to which the writer is for or against a claim is elaborated in this step. The third component includes the presentation of the writer's position in a coherent manner, and relates to the general arrangement and layout of the argument. Therefore, knowledge of how to join and relate sentences logically and smoothly is required to organize the propositions well and to develop the argument both coherently and cohesively.

Cultivating college students' writing ability is a critical part of English teaching. The factors affecting college students' writing ability boil down to three aspects. First, students are not exposed to enough reading and listening materials before they are assigned a writing task. The lack of input of both language and perspectives is to blame for students' lack of critical thinking competence. Second, the writing tasks that are assigned to students are not open, inspiring, or controversial, which do not provide room for open, reflective, and analytical thinking. Third, teachers tend to assess students' writing based on the vocabulary and sentence structures rather than students' critical thinking skills. Thus, students are not encouraged to think independently and critically and put forward creative ideas,

Indeed, students' success in argumentative essay writing is contingent on construing meaningful discourse 
with contextually appropriate linguistic choices. In order to train successful EFL writers, teachers must provide guidance for students through critical analysis, evaluate discourses, and regulate their own writing in terms of both linguistic choices and meaning. Having a theory of critical thinking in which language plays a critical role opens teaching potentials, which may help students with critical appropriation or the construction of meaningful English texts. In other words, a theory-driven curriculum that guides students in understanding and harnessing the correlation between linguistic features and content construction would be best for critical writing instruction. The writer suggests the following approach to foster students' critical thinking in developing argumentative essays.

\subsection{Before Writing-Choosing Online Resources as Learning Materials}

Tomlinson (2012) argues for the importance of materials in the language learning classroom as they are the resources students and teachers depend on to deliver and accumulate knowledge, respectively. Unfortunately, nonetheless, no textbook is perfect as a result of a variety of factors, such as textbook editors' understanding of language learning theory or the demand of a market that might only prefer a particular dimension of language knowledge. To a great extent, in the EFL context, writing textbooks are concerned with the structure or grammar of writing. As a result, teachers and students will be poorly guided in the construction of critical writing at both the language and meaning levels, which call for supplement of the textbooks, online resources from authoritative publishing houses that are verified by English language literacy experts who speak English as native language. In the process of writing, students understand the topic through intensification of external knowledge, which promotes inspiration of intrinsic knowledge. The combination of external knowledge and intrinsic knowledge is the key to successful writing. With information technology development, in addition to newspapers, books, magazines, rich online reading materials, pictures, videos, and documentaries provide us with a rich and vivid multimodal topics and materials, which is an important way to combine reading and writing. Students get the access to a variety of information as well as the judgment of a certain topic from different perspectives. Different news media provide different accounts of the same news event. The following are examples of how the same event is accounted by different news media.

(Example one) CNN: One of China's top tech billionaires faced an unusual interruption to his speech at a company event on Wednesday, when a man walked on stage and drenched him with water. Robin Li, the cofounder and CEO of Chinese tech company Baidu, was speaking about self-driving and connected cars when a young man dressed in a black shirt came on stage and emptied a bottle of water over Li's head. South China Morning Post: Robin Li Yanhong, co-founder and chairman of China search engine giant Baidu, was speaking at a company event on connected cars in Beijing on Wednesday, when a man from the audience jumped on stage and poured a bottle of water over his head. Looking shocked, Li responded by saying "What's your problem?", before the man left the stage and was tackled by security. There were gasps from the audience and then sporadic applause as Li resumed his presentation. Bloomberg: A routine keynote address by Baidu Inc. chief Robin Li morphed into a public humiliation when an unidentified man jumped onstage and doused him in water. The billionaire founder was 10 minutes into introducing an AI-powered valet parking service when a man in a black T-shirt upended a small bottle of water over his head.

(Example two) Associated Press: Niels Hoegel liked to bring about cardiac arrests in his patients by injecting them with overdoses of heart medication and other drugs because he enjoyed the feeling of being able to resuscitate them. Sometimes he succeeded in bringing them back, but in at least 87 cases they died, making him what is believed to be modern Germany's most prolific serial killer. The New York Times: The former nurse's crimes were "incomprehensible," a German judge told the court on Thursday, reaching his arms across the breadth of the bench as if to capture in one gesture what he sensed his words had failed to define-the enormity of murdering 85 patients who had been placed in the care of the nurse but instead had found death. "Your guilt is so large that one can't explain it," the presiding judge, Sebastian Bührmann, told the nurse, Niels Högel, in a courtroom packed with the relatives of the 100 patients whose deaths he was charged with orchestrating. "It is so large; you can't show it."

(Example three) The Telegraph: Britain may have to take back hundred tonnes of unwanted plastic waste from Malaysia after the country's environment minister said it would not be treated as the world's "dumping ground". Yeo Bin Yin singled out the UK for criticism while threatening to return as much as 3,000 tonnes of low-quality plastic to at least 14 countries. The Guardian: For the past year, the waste of the world has been gathering on the shores of south-east Asia. Crates of unwanted rubbish from the west have accumulated in the ports of the Philippines, Indonesia, and Vietnam while vast toxic wastelands of plastics imported from Europe 
and the US have built up across Malaysia. But not for much longer it seems. A pushback is beginning, as nations across south-east Asia vow to send the garbage back to where it came from. Time: The global trash trade has reached a turning point; wealthier nations have long shipped their plastic waste to the developing world to be processed, but in recent months, some nations in Southeast Asia have begun sending the exports-much of it contaminated plastic and trash that is unrecyclable-back to where it came from.

(Example four) The Times: Millions of Britons could be at greater risk from hackers after Google announced that it was cutting services to Huawei smartphones to comply with an order from President Trump. The US technology giant said yesterday that it would no longer provide security updates for the Android operating system to the Chinese company after it was blacklisted by Washington. The Verge: Huawei founder Ren Zhengfei has downplayed the impact of the US executive order that could cripple Huawei's ability to collaborate with American companies like Google and Qualcomm. The Washington Post: A battle between Chinese tech giant Huawei and the United States was "inevitable," its founder said Tuesday, shrugging off any suggestion that Washington would be able to stifle his company's global ambitions. Huawei is at the heart of the trade war between the United States and China, an example-according to the Trump administration-of the way that state-supported Chinese companies have gained an unfair advantage over American ones and are now being used to further China's geopolitical goals.

Materials like the above examples can be provided by teachers before the writing class, and students are required to read them, compare different reports by different media on the same news event, analyze them, provide reasons of the differences and comment on it. The core tenets of critical thinking skills related to English language learners reside in their understanding of language as semiotic resources to participate in discourses and their ability to analyze, evaluate, and regulate communicative discourses.

\subsection{During Writing-Choosing Open, Inspiring and Controversial Tasks}

Teachers need to choose writing tasks that are open, inspiring, and controversial. Open tasks provide room for open thinking, which encourages students to open their minds. Inspiring tasks guide students to think and reflect. Controversial topics encourage dialectical thinking from different perspectives, and help to develop analytical and systematic skills. The following are four good examples of open, inspiring, and controversial writing tasks.

(Example one) Write an essay in response to the passage below. You should discuss the extent to which you agree or disagree with the passage and explain your reasons for the position you take. In developing and supporting your position, you should consider ways in which the author's opinion might or might not hold true and explain how these considerations shape your position.

Have you realized that living simply can make life less stressful and more fulfilling? By getting rid of all but the essentials, choosing to eliminate clutter and chaos, and spending time only on what is important to us, we have more freedom to live and improve. Human beings go astray when they move away from simple living. We are not aware that we have been trapped in the complexity and excess of the modern world. Think about this. Are we as happy as we thought we'd be when we finally possess the many things we wanted? Are we more productive when we are surrounded by numerous inventions and luxuries? Do we have more time for our loved ones when we are chasing more possessions? I doubt it entirely. Yes, I am embracing a minimalist lifestyle, a voluntary "poverty" if you like to call it. Get rid of the excess of life and acquire self-fulfillment and inner joy, before it is too late.

(Example two) Liang Shuming, a Chinese philosopher who spent 70 years of his life seeking an answer to this question, held the belief that the world would get better every day. However, as the fast development of modern society has brought unprecedented challenges to mankind, this lingering question continues to provoke deep thought, reflection, doubt or even fear. For example, Igor Morski, a Polish graphic designer, has created a series of pictures depicting some of the lurking problems in today's world that will endanger rather than improve people's lives. Some scholars even warn that if severe threats like nuclear weapons and climate change remain unchecked, "the doomsday clock is on the verge of striking." What is your answer to this question? Write an essay with your own title clearly stating your opinion and supporting your ideas with reasons and examples.

(Example three) Optimism provides a multitude of benefits across many facets of life. Researchers have linked looking on the bright side to everything from improved pain tolerance to increased longevity. There's no denying the incredible power an optimistic outlook can have on our health, relationships, and performance. But like much in life, it is possible to have too much of a good thing. There are some cases when an overly optimistic outlook can do more harm than good. Suppose there is an online discussion forum on the topic "Can being 
positive backfire?" Write a post to the forum, clearly stating your opinion and supporting your ideas with specific reasons and examples.

(Example four) Read the following passage which presents contradictory views. Write an essay about the issue, stating your opinion and explaining your reasons.

In modern times, we have different ways of long-distance communication. According to a recent survey, in every minute of the day, email users send over 200 million messages and Facebook users share 2.46 million pieces of content. For many people, communication is more convenient and efficient through social media platforms than through meeting people in person. However, there are also voices calling for more face-to-face communication. "Being there", seeing the others present and being seen by them, gives us a stronger sense of shared emotion, solidarity, and respect. For example, a family reunion will be much less meaningful without touching and hugging, seeing faces lighting up and participation in all on-the-spot activities.

The above examples of argumentative tasks serve to guide students to think and reflect, encourage dialectical thinking from different perspectives, and help students to develop analytical and systematic skills. Teachers should encourage students to planning writing by asking questions like: What effect will my position achieve? What theories can support this position? And why is there such a topic? What is the common social phenomenon hidden behind this topic?

\subsection{Post Writing-Teacher Assessment}

English writing is a high-level skill among the four basic skills in English learning and the writing competence is greatly influenced by students' critical thinking skills. However, the traditional teaching theories on college English writing emphasize more on unifying a single pattern of the article structure. Even worse, teachers tend to guide students to memorize the fixed composition templates and classic sentences, neglecting the inspiration of students' critical thinking skills during the process of writing. Consequently, students are not encouraged to think independently and put forward creative ideas, thus producing not-so-high-quality compositions. To be more specific, three problems exist in college English writing teaching in China: First, for a long time, English writing teaching in China puts particular emphasis on textual language skills training, including the analysis and imitation of the surface structure such as vocabulary, syntax, and discourse, with the cultivation of critical thinking skills ignored. Second, many students regard correct grammar, big vocabulary, and neat structures as the standard of excellent writing, neglecting the depth of thinking and inner logic of the writing content. Third, college students generally lack logical thinking abilities such as analysis, comparison, abstraction, generalization, and classification as well as critical thinking skills.

When it's generally a fact that college students lack critical thinking competency, teachers' writing assessment is especially important and can play a critical supporting role by helping students to clear their opinions, learn to think and analyze problems from multiple perspectives.

The assessment of writing ability is a challenging attempt compared with reading, and the literature does not offer a tangible definition of what good writing is. Weigle proposes three different types of rating scales, namely, primary trait scales, holistic scales, and analytic scales. Of these three scoring types, analytic scoring is favored over the other two by specialists for the following reasons. First, it can provide diagnostic data showing writers' strengths and weaknesses. Second, analytic scoring can be most suitably adopted in rater training programs as it can be easily understood and applied by novice raters especially in assessing second language learners' writing. Finally, analytic scoring tends to be more reliable than the other two types. This is probably why analytic scoring is mostly adopted to assess the writing section of standard tests such as the TOEFL and IELTS.

The following are good examples of teacher assessment: The article lacks examples of strong support, so the discussion is slightly empty; Your opinion is clearly expressed, but it is too extreme; There is no proper analysis of the reasonable content of the opposite view. This kind of feedback can make students aware of the insufficiency of speculation, guide students to form and internalize critical thinking, and improve students' attention and cognition of critical thinking.

\section{Conclusion}

Classroom teaching is invested with new features with the application of modern educational resources and methods of education. Teachers can bring into full play advantages of advanced technology, optimize classroom teaching design, and expand the space for students to use critical thinking. Students' success in argumentative essay writing depends to a great extent on their critical thinking competency. In order to train 
successful EFL writers, teachers must guide students through critical analysis, evaluate discourses, and regulate their own writing in terms of both linguistic choices and meaning. The writer suggests a critical approach of three steps to foster students' critical thinking in developing argumentative essays, which include before writing-choosing online resources as learning materials; during writing-choosing open, inspiring and controversial tasks; and post writing-teacher assessment. It is important to note, however, that the acquisition of critical thinking competency and its application in argumentative essays writing can be a slow and long process, depending on students' English proficiency and teachers' instructional skills. In addition, arguably, there are other important dimensions of critical thinking related to argumentative essays writing that were not included in this paper.

\section{References}

1. Barnawi, O. (2011). Finding a Place for Critical Thinking and Self-voice in College English as a Foreign Language Writing Classrooms. English Language Teaching, 4(2): 190-197.

2. Liu, F., \& Stapleton, P. (2014). Counter Argumentation and the Cultivation of Critical Thinking in Argumentative Writing: Investigating Washback from a High-stakes Test. System, 45(1): 117-128.

3. McKinley, J. (2013). Displaying Critical Thinking in EFL Academic Writing: A Discussion of Japanese to English Contrastive Rhetoric. RELC Journal, 44(2): 195-208.

4. Nold, H. (2017). Using Critical Thinking Teaching Methods to Increase Student Success: An Action Research Project. International Journal of Teaching \& Learning in Higher Education, 29(1): 17-32.

5. Paul, R., \& Elder, L. (2006). Critical Thinking Competency Standards. Beijing: Foreign Language Teaching and Research Press.

6. Tomlinson, B. (2012). Materials Development for Language Learning and Teaching. Language Teaching, 45(2): 143179.

7. Tsui, L. (2002). Fostering Critical Thinking Through Effective Pedagogy: Evidence from Four Institutional Case Studies. The Journal of Higher Education, 73(6): 740-763.

8. Wingate, U. (2012). Argument! Helping Students Understand What Essay Writing Is About. Journal of English for Academic Purposes, 11(2): 145-154.

(Editor: Zichen Zhao) 